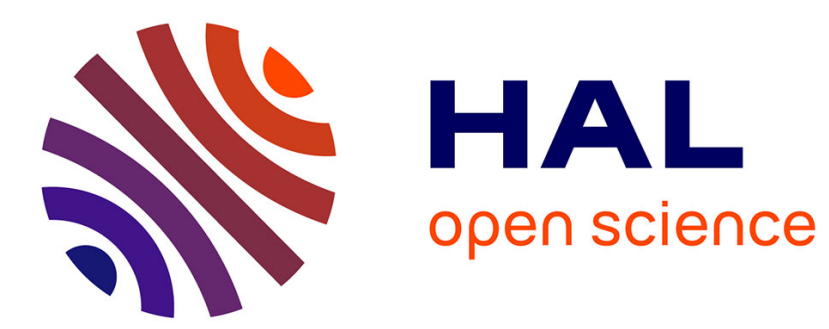

\title{
Optical study of a ZnSe/Zn0.73Mn0.27Se heterostructure
}

\author{
T. Lebihen, E. Deleporte, M. Voos, S. Guha, H. Munekata
}

\section{To cite this version:}

T. Lebihen, E. Deleporte, M. Voos, S. Guha, H. Munekata. Optical study of a ZnSe/Zn0.73Mn0.27Se heterostructure. Journal de Physique IV Proceedings, 1993, 03 (C5), pp.C5-425-C5-428. 10.1051/jp4:1993591 . jpa-00251678

\section{HAL Id: jpa-00251678 https://hal.science/jpa-00251678}

Submitted on 1 Jan 1993

HAL is a multi-disciplinary open access archive for the deposit and dissemination of scientific research documents, whether they are published or not. The documents may come from teaching and research institutions in France or abroad, or from public or private research centers.
L'archive ouverte pluridisciplinaire HAL, est destinée au dépôt et à la diffusion de documents scientifiques de niveau recherche, publiés ou non, émanant des établissements d'enseignement et de recherche français ou étrangers, des laboratoires publics ou privés. 


\title{
Optical study of a $\mathrm{ZnSe} / \mathrm{Zn}_{0.73} \mathrm{Mn}_{0.27} \mathrm{Se}$ heterostructure
}

\author{
T. LEBIHEN, E. DELEPORTE, M. VOOS, S. GUHA ${ }^{(1)}$ and H. MUNEKATA*
}

\author{
Laboratoire de Physique de la Matière Condensée de l'Ecole Normale Supérieure, 24 rue Lhomond, \\ 75005 Paris, France \\ * IBM Research Division, Thomas J. Watson Research Center, P.O. Box 218, Yorktown Heigths, New York \\ 10598 , U.S.A.
}

\begin{abstract}
Photoluminescence, excitation spectroscopy and magneto-photoluminescence experiments are performed up to $5.5 \mathrm{~T}$ at low temperature $(1.7 \mathrm{~K})$ in a $\mathrm{ZnSe} / \mathrm{Zn}_{0.73} \mathrm{Mn}_{0.27} \mathrm{Se}$ double quantum well. The experimental results are compared with calculations of the excitonic transitions, available for a type-I and a type-II band structure. These calculations include the strain effects, the giant Zeeman effect in the ( $\mathrm{Zn}, \mathrm{Mn}) \mathrm{Se}$ layers under a magnetic field, the diamagnetic shift of the exciton. We determine the strain state of the heterostructure and find a quite unusual configuration of the band structure: the fundamental optical transitions of the two wells are type-I light hole transitions, while the excited optical transitions are type-II heavy hole transitions.
\end{abstract}

Among the various II-VI compounds, the ZnSe materials require a particular attention because of their blue emission. As a matter of fact, the first blue laser has been obtained with $\mathrm{ZnSe}$ based compounds [1]. The $\mathrm{ZnSe} /(\mathrm{Zn}, \mathrm{Mn}) \mathrm{Se}$ semimagnetic heterostructures are of particular interest because of their great magneto-optical properties, due to the exchange interaction between the spin of the carriers and the spin of the paramagnetic $\mathrm{Mn}^{2+}$ ions located in $(\mathrm{Zn}, \mathrm{Mn})$ Se layers [2]. The so-called giant Zeeman effect can lead to the formation of a spin superlattice structure in which the carriers can be separated and spatially localized according to their spin $[3,4]$. Moreover, large strains, due to the great lattice mismatch between the binary and the ternary alloys, are present in the structure and strongly modify its band profile. From a comparison between photoluminescence and magneto-photoluminescence experiments and calculations, we demonstrate here that these strains can lead to a quite unusual configuration: the fundamental optical transition is a type-I light hole exciton (electrons and light holes are localized in the same layers), the heavy hole transitions are excited states and correspond to a type-II situation (electrons and heavy holes are localized in adjacent layers).

The heterostructure has been grown by molecular beam epitaxy along the (100) axis and consists in two $\mathrm{ZnSe}$ quantum wells whose thicknesses are $53 \AA$ and $106 \AA$ respectively, separated by a $350 \AA$ thick $\mathrm{Zn}_{0.73} \mathrm{Mn}_{0.27} \mathrm{Se}$ layer. The double quantum well is grown on a $1200 \AA \mathrm{Zn}_{0.73} \mathrm{Mn}_{0.27} \mathrm{Se}$ layer deposited on a $9700 \AA$ thick $\mathrm{ZnSe}$ buffer layer. The cap layer is constituted with a $350 \AA \mathrm{Zn}_{0.73} \mathrm{Mn}_{0.27} \mathrm{Se}$ layer. The substrate is GaAs.

Figure 1 shows the photoluminescence (the excitation wavelength is $4000 \AA$ ) and excitation spectra at low temperature $(1.7 \mathrm{~K})$, performed with a high pressure Xe lamp, followed by a HR320 Jobin-Yvon monochromator. Because the Xe lamp spectrum is not completely flat between $4600 \AA$ and $4000 \AA$, the intensity of the excitation spectra shown in figure 1 is normalized, by making the ratio between the photoluminescence signal and the lamp intensity. Two strong photoluminescence lines are clearly seen at $2775 \mathrm{meV}\left(\mathrm{PL}_{\mathrm{W}}\right)$ and at $2805 \mathrm{meV}\left(\mathrm{PL}_{\mathrm{T}}\right)$. The excitation spectrum of ( $\mathrm{PL}_{\mathrm{W}}$ ) (fig1a) exhibits a strong line $\left(\mathrm{X}_{\mathrm{W}}\right)$ at $2778 \mathrm{meV}$ and a much weaker one ( $\left.\mathrm{Y}_{\mathrm{W}}\right)$ at $2817 \mathrm{meV}$. The excitation spectrum of (PLT) (fig 1b) shows the same features: a strong line $\left(\mathrm{X}_{\mathrm{T}}\right)$ at $2816 \mathrm{meV}$ and a much weaker one $\left(\mathrm{Y}_{\mathrm{T}}\right)$ at $2840 \mathrm{meV}$. (PLw) and $\left(\mathrm{X}_{\mathrm{W}}\right)$ are attributed to the fundamental state of the wide well and $\left(\mathrm{PL}_{\mathrm{T}}\right)$ and $\left(\mathrm{X}_{\mathrm{T}}\right)$ are attributed to the

(1) Present address: 3M Company, 3M Center, St Paul, MN 55144-100, U.S.A. 

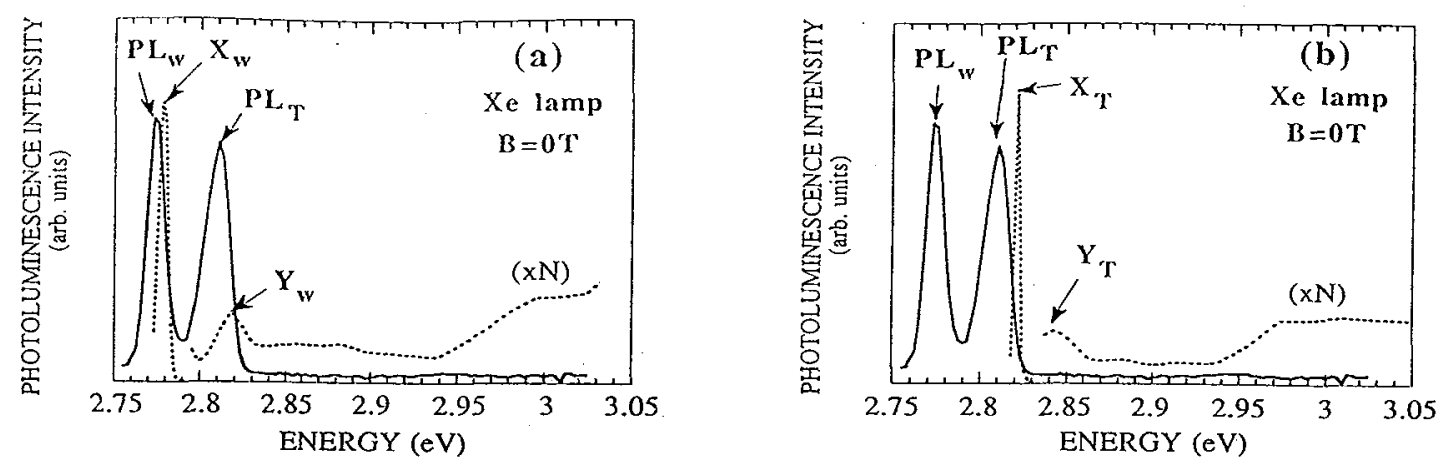

Figure 1: Photoluminescence spectrum (solid curve, excitation energy: $3100 \mathrm{meV}$ ), photoluminescence excitation spectra (dashed curves) (a) of the PLy line (detection energy: $2769 \mathrm{meV}$ ), (b) of the PL $\mathrm{T}_{\mathrm{T}}$ line (detection energy: $2805 \mathrm{meV}$ ), for a $106 \AA / 350 \AA / 53 \AA \mathrm{ZnSe}^{2} \mathrm{Zn}_{0.73} \mathrm{Mn}_{0.27} \mathrm{Se}$ double quantum well . The spectra have been performed with a high pressure Xe lamp, without magnetic field, at low temperature $(1.7 \mathrm{~K})$.

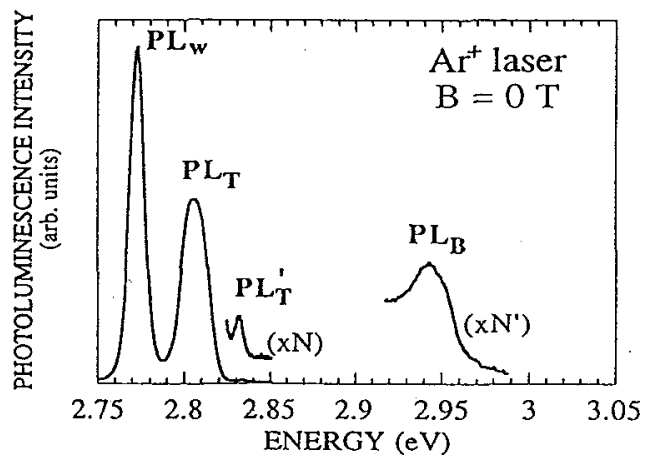

Figure 2: Photoluminescence spectrum of the double quantum well, performed with the $363 \mathrm{~nm}$ line of an $\mathrm{Ar}^{+}$laser, without magnetic field, at low temperature $(1.7 \mathrm{~K})$.

fundamental state of the thinner well. The small Stokes-shift between the $\left(\mathrm{PL}_{\mathrm{W}}\right)$ and $\left(\mathrm{X}_{\mathrm{W}}\right)$ or $\left(\mathrm{PL}_{\mathrm{T}}\right)$ and $\left(X_{T}\right)$, is an indication of the relatively good quality of the sample.

Figure 2 shows the photoluminescence spectrum obtained with the $363 \mathrm{~nm}$ line of an $\mathrm{Ar}^{+}$laser. The incident beam power is much larger in this case. The two strong lines (PLW) and $\left(\mathrm{PL}_{\mathrm{T}}\right)$ are still present at the same energies, but at higher energy, two weak peaks appear: $\left(P L_{B}\right)$ at 2942 meV corresponds to the $\mathrm{Zn}_{0.73} \mathrm{Mn}_{0.27} \mathrm{Se}$ photoluminescence and $\left(\mathrm{PL}_{\mathrm{T}}{ }^{\prime}\right)$ is at the same energy than $\left(\mathrm{Y}_{\mathrm{T}}\right)$ in figure $1 \mathrm{~b}$. In fact, it is possible to see excited transitions in the photoluminescence spectrum because of the large electronic temperature.

To interpret these experimental data, we have performed a calculation of the transition energies, which takes into account the strain effects resulting from the lattice mismatch and the excitonic effects.

The influence of the strain on the band structure has been calculated, using the elastic constants and deformation potentiels given in ref. [5,6]. If the $1200 \AA \mathrm{Zn}_{0.73} \mathrm{Mn}_{0.27} \mathrm{Se}$ layer, grown on the $\mathrm{ZnSe}$ buffer layer, is not fully relaxed, the barrier layers will be strained. We take as a parameter the residual strain in the barrier: $\varepsilon_{b a r}=\frac{a-a^{0}(x)}{a}$ where $a$ is the mean parameter in the strained layer, and $a^{0}(x)=5.666+0.268 . x$ $\AA$ [7] is the strain-free lattice constant of $\mathrm{Zn}_{1-\mathrm{x}} \mathrm{Mn}_{\mathrm{x}} \mathrm{Se}$. We assume an elastic accomodation of the lattice parameter of the two $\mathrm{ZnSe}$ wells with the barrier one.

As an example we have represented in figure 3 the band extrema structure for two extreme situations: (a) the barrier layer fully relaxed, (b) the barrier layer fully strained by the ZnSe buffer. The percentage of the strain-free gap difference which is in the valence band, called the relative valence band offset $\mathrm{qv}^{0}$, is assumed to be $10 \%$. In these two cases, the band structure is type-I for the light holes, type-II for the heavy holes. 


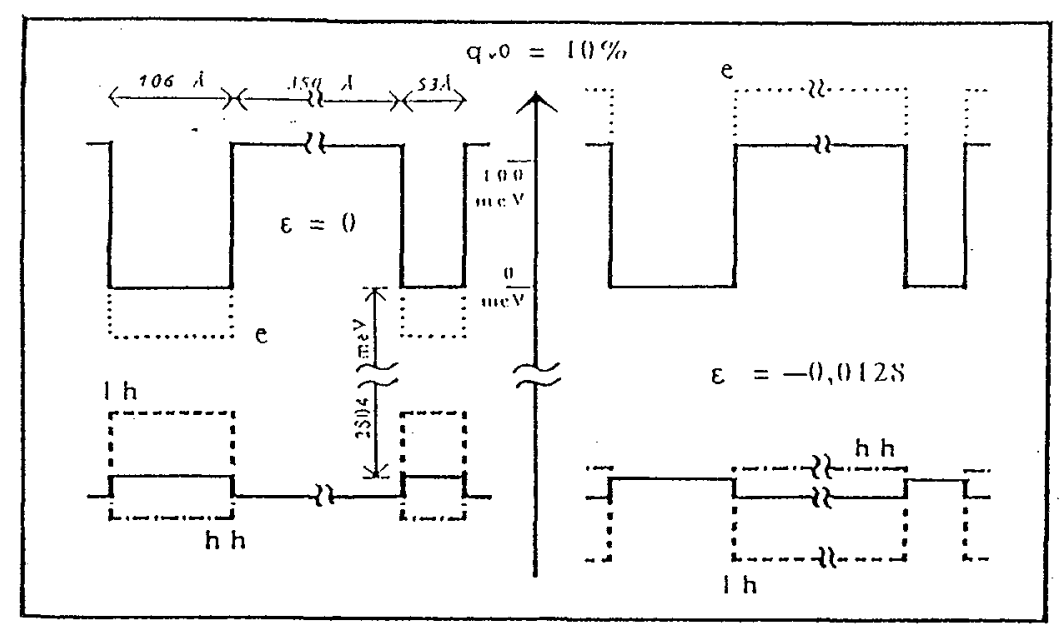

Figure 3: Potential profile along the growth axis without strain (solid line) and with strain for the conduction band (dotted line), the valence band for the heavy holes (dashed-dotted line) and for the light holes (dashed line). The assumed relative strain-free valence band offset is $q_{v}{ }^{0}=10 \%$. Two cases are represented: (a) the barrier layer is fully relaxed $\varepsilon_{\mathrm{bar}}=0$, (b) the barrier layer is fully strained by the $\mathrm{ZnSe}$ buffer: $\varepsilon_{\text {bar }}=-0.0128$.

Knowing the band profile, a variational calculation of the excitonic transitions, which takes into account the possible type-II nature of the band profile has been performed [8]. The effective masses and the dielectric constant are taken from ref. [9], the energy gap of $\mathrm{Zn}_{1-\mathrm{x}} \mathrm{Mn}_{\mathrm{x}} \mathrm{Se}$ is taken from ref. [10]. For a type-II band structure, the coulombic interaction creates two interface excitons [8]. The thinner is the $\mathrm{ZnSe}$ well, the stronger is the interface exciton, because of the larger penetration of the electron wavefunction in the barrier. For a type-I band structure, we have checked that the $350 \AA \mathrm{Zn}_{0.73} \mathrm{Mn}_{0.27} \mathrm{Se}$ barrier was large enough to avoid the coupling between the two wells. The light hole transitions are found to be very sensitive on the value of $\varepsilon_{\mathrm{bar}}$, as it can be understood in figure 3, and independant of $\mathrm{qv}^{0}$. On the contrary, the heavy hole transitions are not very sensitive to $\varepsilon_{\text {bar }}$ but depends strongly on $\mathrm{q}_{\mathrm{v}}{ }^{0}$ (at least for $\mathrm{q}_{\mathrm{v}}{ }^{0}<15 \%$, for which the band structure is type-П).

From the comparison between the experimental and theoretical results, we deduce that the fundamental states $\left(\mathrm{X}_{\mathrm{W}}\right)$ and $\left(\mathrm{X}_{\mathrm{T}}\right)$ of the two quantum wells are light hole transitions and that the excited transitions $\left(\mathrm{Y}_{\mathrm{W}}\right)$ and $\left(\mathrm{Y}_{\mathrm{T}}\right)$ are heavy hole transitions. From the energy position of $\left(\mathrm{X}_{\mathrm{W}}\right)$ and $\left(\mathrm{X}_{\mathrm{T}}\right)$, we find that the $(\mathrm{Zn}, \mathrm{Mn})$ Se layers are compressed: $\varepsilon_{\mathrm{bar}}=-5.5 \cdot 10^{-3}$. As the light hole transitions are not sensitive to the relative band offset, this value of the strain is not dependant on $\mathrm{q}_{\mathrm{v}}{ }^{0}$. The experimental energy position of the heavy hole transitions is consistent with $\mathrm{q}_{\mathrm{v}}{ }^{0}=10 \%$.

The magneto-photoluminescence experiments can provide an affirmation of our precedent findings, because these experiments allow us to identify the nature of the transitions. In fact, the magnetic field induced variation of the energy position of the lines originates from the giant Zeeman effect present in the $\mathrm{Zn}_{0.73} \mathrm{Mn}_{0.27} \mathrm{Se}$ layers [2], which is three times larger for the heavy holes than for the light holes. The calculation of the excitonic transitions, taking into account the Zeeman splitting of the barrier band edges and the diamagnetic shift of the exciton like in ref [8] shows that the magnetic field induced (up to 5T) redshift of the light hole transitions is a few meV at the most, while heavy hole transitions redshift is at least $10 \mathrm{meV}$.

The magneto-photoluminescence experiments have been performed at low temperature $(1.7 \mathrm{~K})$ with a superconducting magnet up to 5.5T, in the Faraday configuration, the laser (363 nm line of the $\mathrm{Ar}^{+}$laser) ingoing and the photoluminescence outgoing lights were collected by a multi-fiber-optic guide. Figure 4 shows the energy position of the $\left(\mathrm{PL}_{\mathrm{W}}\right),\left(\mathrm{PL}_{\mathrm{T}}\right),\left(\mathrm{PL}_{\mathrm{T}}\right),\left(\mathrm{PL}_{\mathrm{B}}\right)$ lines versus the magnetic field. The $\left(\mathrm{PL}_{\mathrm{T}}\right)$ line is visible only up to $1.5 \mathrm{~T}$, above this value, $\left(\mathrm{PL}_{\mathrm{T}}\right)$ disappears in the strong $\left(\mathrm{PL}_{\mathrm{T}}\right)$ line. 


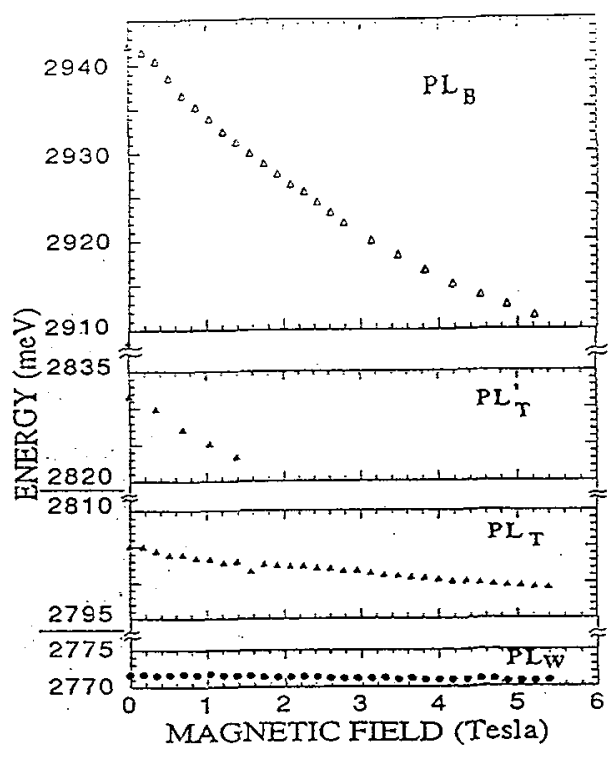

Figure 4: Magnetic field induced variation of the ( $\left.\mathrm{PL}_{\mathrm{W}}\right),\left(\mathrm{PL}_{\mathrm{T}}\right),\left(\mathrm{PL}_{\mathrm{T}}\right)$ and $\left(\mathrm{PL}_{\mathrm{B}}\right)$ photoluminescence lines, up to 5.5T, at low temperature $1.7 \mathrm{~K}$
Firstly, the magnetic field induced redshift of the barrier photoluminescence $\left(\mathrm{PL}_{\mathrm{B}}\right)$, which is 30 $\mathrm{meV}$ for $5.5 \mathrm{~T}$ and has the look of a Brillouin function [2], is consistent with the redshift of a heavy hole transition. This confirms the heavy hole character of the fundamental transition in the barrier and thus the negative sign of $\varepsilon_{\mathrm{bar}}$. Secondly, the ( $\mathrm{PLW}$ ) line does not move at all with the magnetic field and (PLT) line exhibits a small redshift of $5 \mathrm{meV}$ up to $5.5 \mathrm{~T}$. The small observed redshifts are consistent with the light hole character of the fundamental states of the two wells. The $\left(\mathrm{PL}_{\mathrm{T}}\right)$ variation is larger than the $\left(\mathrm{PL}_{\mathrm{W}}\right)$ variation, because the hole wavefunction of the the thinner well has a larger probability density in the barrier than the one of the wide well. Finally, the fact that the $\left.\left(\mathrm{PL}_{\mathrm{T}}\right)^{\prime}\right)$ line redshift is quite parallel to the barrier photoluminescence redshift, at least up to $1.5 \mathrm{~T}$, confirms the heavy hole character of this transition and the large penetration of the hole wavefunction in the ( $\mathrm{Zn}, \mathrm{Mn}) \mathrm{Se}$ layer, indicating the type-II character of the band structure for the heavy holes. Moreover the weak luminescence intensity of the heavy hole transitions $\left(Y_{W}\right)$ and $\left(\mathrm{Y}_{\mathrm{T}}\right)$ in figure 1 is an additional proof of the typeII character of the heavy hole band structure.

In conclusion, magneto-photoluminescence experiments have allowed us to identify the nature of the optical transitions observed in the photoluminescence and excitation spectra at $B=0 \mathrm{~T}$. From the comparison between the experimental results and the calculations, an estimation of the strain effects in the structure has been performed: the $1200 \AA \mathrm{Zn}_{0.73} \mathrm{Mn}_{0.27}$ Se layer is partially relaxed on $\mathrm{ZnSe}$ buffer layer, the ( $\left.\mathrm{Zn}, \mathrm{Mn}\right) \mathrm{Se}$ barrier layers are compressed. We have found that the fundamental optical transitions of our two uncoupled wells are type-I light hole excitons. The heavy hole transitions are excited transitions and correspond to a type-II band structure. From these results, we have obtained an estimation of the relative valence band offset: $\mathrm{qv}^{0}=10 \%$. This value of $\mathrm{qv}^{0}$ is consistent with the small values usually found in the literature $[3,4]$. As the magnetic field induced redshift is much larger for the heavy hole transitions than for the light hole transitions, we expect that the heavy hole transitions will become the fundamental excitonic states for a certain magnetic field. We have to perform magneto-photoluminescence up to a higher field, in order to confirm this phenomenon.

\section{References:}

[1] M. Haase, J. Qiu, J. De Puydt, H. Cheng, Appl. Phys. Lett. 59 (1991) 1272.

[2] A. Twardowski, T. Dietl, N. Demianiuk, Solid State Comm. 48 (1983) 845.

[3] Y. Hefetz, J. Nakahara, A.V. Nurmikko, L.A. Kolodziejski, R.L. Gunshor, S. Datta, Appl. Phys. Lett. 47 (1985) 989.

[4] B.T. Jonker, X. Liu, W.C. Chou, A. Petrou, J. Warnock, J.J. Krebs, G.A. Prinz, J. Appl. Phys. 69 (1991) 6097.

[5] A. Blacha, H. Presting, M. Cardonna, Phys. Stat. Sol. (b) 126 (1984) 11.

[6] I. Berlincourt, H. Jaffe, L.R. Shiozawa, Phys. Rev 129 (1963) 1009.

[7] L.A. Kolodziejski, R.L. Gunshor, R. Venkatasubramanian, T.C. Bonsett, R. Frohne, S. Datta, N. Otsuka, R.B. Bylsma, W.M. Becker, A.V. Nurmikko, J. Vac. Sci. Technol. B4 (1986) 583.

[8] G. Peter, E. Deleporte, G. Bastard, J.M. Berroir, C. Delalande, B. Gil, J.M. Hong, L.L. Chang, J. of Lumin. 52 (1992) 147.

[9] Landolt-Börnstein Tables, Vol. III/22a, Eds. O. Madelung and M. Schulz (Springer, Berlin, 1987.

[10] R.B. Bylsma, J. Kossut, W.M. Becker, L.A. Kolodziejski, R.L. Gunshor, R. Frohne, J. Appl. Phys. 61 (1987) 3011. 